\title{
Antibiotic resistance of Streptococcus pneumoniae, isolated from nasopharynx of preschool children with acute respiratory tract infection in Lithuania
}

Indrè Stacevičiene $\dot{e}^{1,2}$, Sigita Petraitiené $\dot{1}^{1,2}$, Daiva Vaičiūniené $\dot{e}^{1,2}$, Tomas Alasevičius $^{1,2}$, Jūratè Kirsliené2 and Vytautas Usonis i, $^{1 *}$

\begin{abstract}
Background: Increasing pneumococcal resistance to commonly used antibiotics and multidrug resistance is a serious public health concern. Data on distribution of resistant Streptococcus pneumoniae (SPn) strains among children in Lithuania are limited. We evaluated the circulation of SPn serotypes and antimicrobial susceptibility among preschool children in Lithuania before the introduction of universal infant pneumococcal vaccination.

Methods: A prospective study was carried out from February 2012 to March 2013 in five cities of Lithuania. A total of 900 children under six years of age who presented to primary care centre or a hospital emergency department with acute respiratory tract infection were enrolled in the study. Nasopharyngeal swabs were obtained and cultured for SPn. Positive samples $(n=367)$ were serotyped and tested for antimicrobial susceptibility. Associations of pneumococcal non-susceptibility with study site, season, age, sex, attendance of day care centre and treatment with antimicrobials (between one and six months prior the study) were evaluated.

Results: About a half (56.7 \%) of SPn strains were susceptible to all the antibiotics tested. Pneumococcal non-susceptibility to penicillin, erythromycin, clindamycin and trimethoprim-sulphamethoxazole was 15.8, 21.3, 16.9 and $27.3 \%$, respectively. None of the tested isolates was resistant to norfloxacin or vancomycin. We found a geographical variation of pneumococcal resistance within the cities of the country. Age, sex, the attendance of day care centre and treatment with antimicrobials prior the study was not significantly associated with a carriage of non-susceptible SPn strains. Among non-susceptible SPn serotypes $67.9 \%-82.4 \%$ were present in currently available pneumococcal conjugate vaccines.

Conclusions: The rates of nasopharyngeal SPn susceptibility to penicillin and macrolides are still high among preschool children in Lithuania, however they are lower compared with previous studies. A strict policy with respect to antibiotic prescription together with widespread use of vaccination could potentially reduce the carriage rate of antibiotic-resistant pneumococci in our country.
\end{abstract}

Keywords: Streptococcus pneumoniae, Antibiotic resistance, Nasopharyngeal colonization, Preschool children, Respiratory tract infection

\footnotetext{
* Correspondence: vytautas.usonis@mf.vu.lt

${ }^{1}$ Clinic of Children's Diseases, Faculty of Medicine, Vilnius University,

Santariskiu Str. 4, Vilnius, Lithuania

${ }^{2}$ Children's Hospital, Affiliate of Vilnius University Hospital Santariskiu Klinikos,

Santariskiu Str. 7, Vilnius, Lithuania
} 


\section{Background}

Streptococcus pneumoniae (SPn) colonises the nasopharynx and it may be asymptomatic or result in various types of diseases including acute otitis media, sinusitis, pneumonia, sepsis and meningitis, which are a considerable burden $[1,2]$. World Health Organization (WHO) estimated that at the beginning of infants vaccination with pneumococcal conjugated vaccines (PCV) 14.5 million cases of serious illness and $7 \%$ of all cause-child mortality [3] under five years of age were due to pneumococcal infections. Despite the effectiveness of PCV vaccination in different countries, WHO reports that pneumococcal related deaths among children under five years of age remains high [4]. Increasing pneumococcal resistance to commonly used antibiotics such as macrolides or cephalosporins and multidrug resistance is another serious public health concern [5].

Antibiotic susceptibility of SPn has a large variation among European countries. For example, non-susceptibility to penicillin of non-invasive SPn isolates varies from $1.7 \%$ in Norway [6] to $83 \%$ in Romania [7] and nonsusceptibility to erythromycin varies from $1.2 \%$ in the Czech Republic [8] to $65.5 \%$ in Italy [9]. Due to geographical diversity of the resistance of SPn strains dependent on the local antimicrobial policy, epidemiological studies in each geographical region are needed [10].

Data on distribution of resistant SPn strains among children in Lithuania are limited. Only 37 and 59 SPn strains, which caused invasive pneumococcal diseases in children and adults, were tested for antimicrobial susceptibility in our country in 2012 and 2013, respectively [11]. These findings do not necessarily reflect the actual antimicrobial susceptibility of SPn in Lithuania and to the moment there is no official data describing invasive pneumococcal resistance among paediatric patients.

Three studies of SPn nasopharyngeal carriage and antimicrobial susceptibility in healthy children have been performed previously (in 1999, 2001 and 2006) [12, 13], in which a total of 1625 children from the same 13 day-care centres were enrolled. Non-susceptibility to penicillin increased from $6.3 \%$ in 1999 to $9.6 \%$ in 2006. Higher increase of non-susceptibility was observed to erythromycin: 4.7 in 1999 and $9.6 \%$ in 2006. These studies were rather limited because all of them were performed during a short period of time (in February and March) and the data presented only one city of the country (Vilnius).

Our study performed in 2012-2013 evaluated the circulation of SPn serotypes and antimicrobial susceptibility among children with acute respiratory tract infection (RTI) under six years of age in Lithuania before the introduction of universal infants PCV vaccination in the country in October 2014 [14]. At the time of the study two PCVs (10-valent (PCV-10) and 13-valent (PCV-13)) were available only on private market. PCV vaccination coverage was unknown but probably it was low as vaccination costs were relatively high and not reimbursed. Results of this study might be the background for further investigations on the impact of PCV vaccination on the distribution of resistant SPn serotypes in Lithuania, including the widely discussed phenomenon of replacement in circulating resistant SPn serotypes due to vaccination [15]. SPn colonisation rate, serotype distribution and the influence on the clinical outcome were published separately $[16,17]$.

\section{Methods}

This prospective study was carried out from February 2012 to March 2013. Eight primary care centres (PCC) in Lithuania's five cities (Vilnius $(n=2)$, Kaunas $(n=2)$, Klaipeda $(n=2)$, Panevezys $(n=1)$, Alytus $(n=1))$ from all main regions of the country and emergency department (ED) of Children's Hospital, Affiliate of Vilnius University Hospital Santariskiu Klinikos in Vilnius were involved in examining children for SPn nasopharyngeal carriage and antimicrobial susceptibility.

Children under six years old, who visited a primary care physician or a paediatrician because of either upper or lower acute RTI, were enrolled into the study. The main symptoms of acute RTI were acute onset, fever $\left(37.2{ }^{\circ} \mathrm{C}\right.$ or higher), runny nose, sneezing, cough and sore throat. Children were excluded if another cause of fever was identified (e.g., confirmed urinary tract infection, etc.). Children were not included if they had been vaccinated with any pneumococcal vaccine (because of the vaccine's effect on reducing colonization with vaccine serotypes [18]) or had taken antibiotics within one month prior the enrolment (as this can diminish the yield of nasopharyngeal culture samples [19]).

Nasopharyngeal swabs were taken at the time of enrolment in the study using Culturette with Amies transport medium (Deltalab, Spain) and transported to a certified laboratory of Children's Hospital, Affiliate of Vilnius University Hospital Santariskiu Klinikos in Vilnius within $48 \mathrm{~h}$ from collection. Hare et al. compared several methods for nasopharyngeal samples transport and found Amies transport medium adequate for SPn detection [20]. However, according WHO skim milk-tryptone-glucoseglycerol (STGG) remains the medium of choice for transport and storage of nasopharyngeal swabs [21].

Classic cultural methods (cultivation in $5 \% \mathrm{CO}_{2}$, colony morphology, Gram staining, catalase test, optochin sensitivity) were used to isolate SPn from the swabs [21, 22]. All the isolates were sensitive to optochin. Bacterial antigen rapid latex agglutination test (Wellcogen, Remel Europe Limited, United Kingdom) was used for the confirmation. Serotypes were determined by means of latex agglutination reaction using the Pneumotest-Latex kit and selected Latex Factor sera: 6b, 6c, 7b, 9 g, 18c, 18f, 19b, 19c and 23b (Statens Serum Institut, Copenhagen, Denmark).

SPn susceptibility to penicillin was determined by diskdiffusion method using $1 \mu \mathrm{g}$ oxacillin disk (Bio-Rad, 
France). Isolates showing inhibition zones $\leq 19 \mathrm{~mm}$ were confirmed by the penicillin Etest (bioMerieux, France). Breakpoints of minimal inhibitory concentrations (MICs) were interpreted according to the European Committee on Antimicrobial Susceptibility Testing recommendations (EUCAST, 2012) [23]. SPn strains were defined as penicillin susceptible SPn (PSSP, MIC $\leq 0.06 \mathrm{mg} / \mathrm{l}$ ), penicillin intermediate SPn (PISP, MIC >0.06-2.0 mg/l) and penicillin resistant SPn (PRSP, MIC $>2 \mathrm{mg} / \mathrm{l}$ ). PISP and PRSP were grouped as penicillin non-susceptible SPn (PNSP).

Susceptibility to erythromycin, clindamycin, trimethoprim-sulphamethoxazole, norfloxacin and vancomycin was determined by disk-diffusion method using Mueller-Hinton agar, containing horse blood $5 \%$ and $20 \mathrm{mg} /$ l $B$-nicotinamide adenine dinucleotide (Bio-Rad, France). Inoculated plates were incubated at $37{ }^{\circ} \mathrm{C}$ in $5 \% \mathrm{CO}_{2}$. Results were interpreted according to EUCAST, 2012 [23]. Multidrug resistance (MDR) was defined as nonsusceptibility to penicillin and $\geq 2$ other non- $\beta$-lactam antimicrobial classes [24].

\section{Statistical analysis}

The data were analysed using SPSS (Statistical Package for the Social Sciences) software 16. Multivariable Poisson regression with robust variance estimation was used to assess the association of study site (PCCs of Kaunas, Klaipeda, Panevezys vs Vilnius ED and PCC), season (spring, autumn, winter vs summer), age (24-47 and 48-71 vs 0-23 months), sex (male vs female) and attendance of day care centre (DCC; non-attending vs attending) with SPn non-susceptibility. Univariable Poisson regression with robust parameter estimates was used to analyse the associations of pneumococcal nonsusceptibility to separate antibiotics with sex, study site, and treatment with antimicrobials (between one and six months prior the study). Cross tabulation with chisquared test was used to test statistical significance for differences between two groups. Statistical significance was defined by $p<0.05$.

\section{Results}

The data collected from the 900 study participants during the one-year study period were analysed: 636 patients at the PCCs and 264 at the hospital ED. The enrolled children comprised 408 girls and 492 boys under six years of age with acute RTI. The distribution of enrolled children by sex and age was similar in all the cities, with the exception of Alytus, which may be due to a very small number of study participants in this city $(n=18)$ [16].

A total of 367 SPn strains (one per patient) were isolated from the 900 samples collected, giving a colonisation rate of $40.8 \%$. A detailed analysis of SPn colonisation and serotype distribution in relation to various factors were published separately $[16,17]$.
All isolated SPn strains $(n=367)$ were tested for antimicrobial susceptibility. About a half $(56.7 \%, n=208)$ of SPn strains were susceptible to all the antibiotics tested and $76 \%(n=279)$ were susceptible to penicillin and macrolides. A single drug resistance was observed in $24.0 \%(n=88)$ of SPn isolates with a predominance of non-susceptibility to trimethoprim-sulphamethoxazole $(19.3 \%, n=71)$. Dual resistance was present in $5.2(n=19)$ and MDR - in $12.5 \%$ $(n=46)$ of SPn isolates.

The highest penicillin MIC was $2 \mathrm{mg} / \mathrm{l}$. Hence, according to the 2012 EUCAST breakpoints [23], none of the strains fell into the resistant category, but $15.8 \%(n=58)$ were PISP. Only $12.1 \%(n=7)$ of PISP were susceptible to other antibiotics tested while other PISP were concomitantly non-susceptible to erythromycin $(82.8 \%, n=48)$, clindamycin $(77.6 \%, n=45)$ or trimethoprim-sulphamethoxazole $(34.5 \%, n=20)$. In addition, $8.6(n=5)$ of PISP showed dual resistance, while $51.7(n=30)$ and $27.6 \%(n=16)$ were resistant to 3 or 4 antibiotics tested, respectively.

SPn resistance to clindamycin was $16.9 \%(n=62)$. Higher rates of resistance were present to erythromycin: 21.0 $(n=77)$ were resistant and $0.3 \%(n=1)$ was intermediately susceptible. The highest non-susceptibility rates of pneumococci were found to trimethoprim-sulphamethoxazole, whereas $21.0(n=77)$ were resistant and $6.3 \%(n=23)$ intermediately susceptible. None of the tested isolates was resistant to norfloxacin and vancomycin.

The rate of SPn antimicrobial non-susceptibility in relation to various factors is summarized in Table 1. Antibiotic non-susceptibility of SPn was similar at ED compared with PCCs, 44.6 (54/121) and $42.7 \%$ (105/ 246) respectively (PR (95\% CI) - 1.035 (0.854-1.255), $p=0.724)$. A detailed analysis revealed a higher prevalence of PISP and MDR SPn at PCCs compared with ED (19.1 \% vs $9.1 \%$, PR (95\% CI) - 2.102 (1.131-3.904), $p=0.019$ for PISP and $15.4 \%$ vs $6.6 \%$, PR (95\% CI) $2.336(1.125-4.852) p=0.023$ for MDR SPn, respectively). Differences of SPn susceptibility to erythromycin, clindamycin and trimethoprim-sulphamethoxazole among those isolated from patients at PCCs and the ED of the hospital were not statistically significant ( $p=$ $0.641, p=0.188$ and $p=0.613$, respectively).

Antimicrobial non-susceptibility of SPn varied in different studied sites of Lithuania: the highest rates were found in Vilnius and the lowest - in Klaipeda (Table 1). Higher rates of MDR and non-susceptibility to penicillin, erythromycin and clindamycin were found in Panevezys while non-susceptibility to trimethoprim-sulphamethoxazole was more common in Vilnius (Fig. 1). Alytus was excluded from this comparison because of the small number of SPn isolates $(n=18)$. Sex and age were not significantly associated with carriage of non-susceptible SPn strains (Table 1) but there was a tendency of higher non-susceptibility to erythromycin (25.5\% vs $17.8 \%$, PR 
Table 1 Streptococcus pneumoniae non-suscebtibility in relation to various factors

\begin{tabular}{|c|c|c|c|c|c|c|}
\hline \multicolumn{2}{|l|}{ Characteristic } & Susceptible isolates $(n=208), \mathrm{n}(\%)$ & Non-susceptible isolates $(n=159), \mathrm{n}(\%)$ & Total $(n=367)$ & PR $(95 \% \mathrm{Cl})$ & $P$ value \\
\hline \multicolumn{7}{|l|}{ Age (months) } \\
\hline \multicolumn{2}{|l|}{$0-23^{b}$} & 49 (53.3) & $43(46.7)$ & 92 & & \\
\hline \multicolumn{2}{|l|}{$24-47$} & $117(58.8)$ & $82(41.2)$ & 199 & $0.953(0.858-1.059)$ & 0.370 \\
\hline \multicolumn{2}{|l|}{$48-71$} & $42(55.3)$ & $34(44.7)$ & 76 & $0.992(0.874-1.125)$ & 0.895 \\
\hline \multicolumn{7}{|l|}{ Sex } \\
\hline \multicolumn{2}{|l|}{ Male } & $114(56.4)$ & $88(43.6)$ & 202 & $1.006(0.937-1.081)$ & 0.864 \\
\hline \multicolumn{2}{|l|}{ Female $^{b}$} & $94(57.0)$ & $71(43.0)$ & 165 & & \\
\hline \multicolumn{7}{|c|}{ Day care centre attendance } \\
\hline \multicolumn{2}{|l|}{ Attending $^{\mathrm{b}}$} & $153(56.7)$ & $117(43.3)$ & 270 & & \\
\hline \multicolumn{2}{|c|}{ Non-attending } & $53(56.4)$ & $41(43.6)$ & 94 & $1.013(0.912-1.126)$ & 0.808 \\
\hline \multicolumn{7}{|l|}{ Season } \\
\hline \multicolumn{2}{|l|}{ Spring } & $72(52.9)$ & $64(47.1)$ & 136 & $1.181(1.024-1.363)$ & 0.022 \\
\hline \multicolumn{2}{|l|}{ Summer ${ }^{b}$} & $23(71.9)$ & $9(28.1)$ & 32 & & \\
\hline \multicolumn{2}{|l|}{ Autumn } & $78(59.1)$ & $54(40.9)$ & 132 & $1.097(0.947-1.270)$ & 0.219 \\
\hline \multicolumn{2}{|l|}{ Winter } & $35(52.2)$ & $32(47.8)$ & 67 & $1.154(0.990-1.344)$ & 0.067 \\
\hline \multicolumn{7}{|c|}{ Cities of Lithuania } \\
\hline \multirow[t]{3}{*}{ Vilnius } & PCC & $45(52.3)$ & $41(47.7)$ & 86 & & \\
\hline & ED & $67(55.4)$ & $54(44.6)$ & 121 & & \\
\hline & Total $^{\mathrm{b}}$ & $112(54.1)$ & $95(45.9)$ & 207 & & \\
\hline Kaunas & PCC & $31(59.6)$ & $21(40.4)$ & 52 & $0.939(0.843-1.046)$ & 0.253 \\
\hline Klaipeda & PCC & $17(70.8)$ & $7(29.2)$ & 24 & $0.870(0.733-1.033)$ & 0.112 \\
\hline Panevezys & PCC & $47(57.3)$ & $35(42.7)$ & 82 & $0.985(0.891-1.090)$ & 0.774 \\
\hline Alytus $^{a}$ & PCC & $1(50.0)$ & $1(50.0)$ & 2 & & \\
\hline
\end{tabular}

PCC primary care centre, ED the emergency department of Children's Hospital, Affiliate of Vilnius University Hospital Santariskiu Klinikos, Vilnius. PR (95 \% Cl) prevalence ratio and $95 \%$ confidence interval of Streptococcus pneumoniae non-susceptibility to one or more antibiotics tested (penicillin, erythromycin, clindamycin, trimethoprim-sulphamethoxazole, norfloxacin and vancomycin), using Multivariable Poisson regression

${ }^{a}$ Note that Alytus was excluded from this comparison because of the small number of $S$. pneumoniae isolates $(n=2)$

${ }^{\mathrm{b}}$ Reference group for each comparison

(95\% CI) - $1.428(0.962-2.120), p=0.077)$ and clindamycin (20.0\% vs $14.4 \%$, PR (95\% CI) - 1.393 (0.884-2.195), $p=0.153)$ in girls compared with boys. SPn nonsusceptibility to different antibiotics was similar among age groups (Table 2). The attendance of DCC had no significant effect to the susceptibility of pneumococci (Table 1).

A significant decrease of non-susceptibility to all tested antibiotics was observed in summer compared to spring (Table 1), but the differences to separate antibiotics were not statistically significant. The rate of susceptible SPn strains did not differ significantly between children who were treated with antimicrobials during the period between one and six months prior the nasopharyngeal sample and children who were not $(52.0 \%(51 / 98)$ vs $57.4 \%(143 / 249)$, PR (95 \% CI) - 0.906 (0.729-1.127), $p=0.376)$.

The most common serotypes of non-susceptible SPn strains were $19 \mathrm{~F}$ (20.8, 33/159), 14 (15.7, 25/159), 6B (14.5, 23/159), 15 (13.8, 22/159) and $23 \mathrm{~F}$ (13.8 \%, 22/159). Serotype distribution of SPn strains non-susceptible to different antibiotics are shown in Fig. 2. Among non- susceptible serotypes $67.9(108 / 159)$ were present in PCV10 (serotypes 1, 4, 5, 6B, $7 \mathrm{~F}, 9 \mathrm{~V}, 14,18 \mathrm{C}, 19 \mathrm{~F}$ and $23 \mathrm{~F})$ and $82.4 \%(131 / 159)$ in PCV13 (serotypes 1, 3, 4, 5, 6A, 6B, 7 F, 9 V, 14, 18C, 19A, $19 \mathrm{~F}$ and $23 \mathrm{~F}$ ). Among MDR serotypes $73.9(34 / 46)$ were present in PCV10 and $84.8 \%(39 / 46)$ in PCV13.

\section{Discussion}

\section{Susceptibility of non-invasive S. pneumoniae}

The data presented illustrate the resistance of noninvasive SPn to antimicrobials among preschool children before the introduction of universal infants PCV vaccination.

The rate of PSSP was quite high (84.2\%) and there were no PRSP strains found in the nasopharynx. Similar results were observed among invasive SPn isolates from children and adults in our country during the study years: 83.8 in 2012 and $76.3 \%$ in 2013 [11]. However, our findings indicates lower PSSP rates than those in healthy children aged 2-7 years in the previous nasopharyngeal carriage studies 


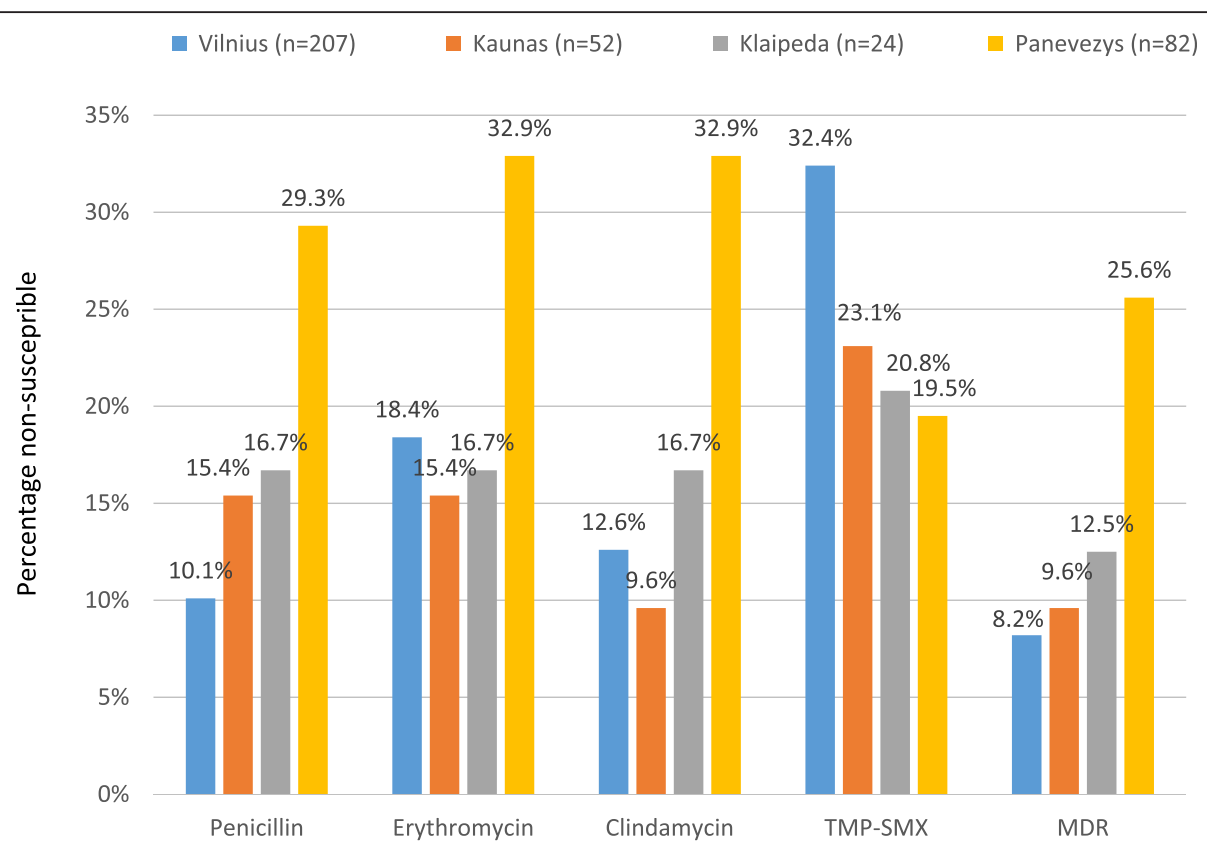

Fig. 1 Distribution of non-susceptible Streptococcus pneumoniae nasopharyngeal strains in the study sites of Lithuania. TMP-SMX - trimethoprimsulphamethoxazole; MDR - multidrug resistance. Study sites were primary care centres of Vilnius, Kaunas, Klaipeda, Panevezys and Alytus and the emergency department of Children's Hospital, Affiliate of Vilnius University Hospital Santariskiu Klinikos in Vilnius. Note that Alytus was excluded from this comparison because of the small number of S. pneumoniae isolates $(n=2)$. Using univariable Poisson regression analysis, significant differences were found in these comparisons: non-susceptibility to penicillin was higher in Panevezys vs Vilnius (PR: 2.885, $p=0.000$ ), non-susceptibility to enythromycin was higher in Panevezys vs Vilnius (PR: 1.794, $p=0.007$ ) and Kaunas (PR: 2.140, $p=0.035$ ), resistance to clindamycin was higher in Panevezys vs Vilnius (PR: $2.621, p=0.000)$ and Kaunas (PR: 3.424, $p=0.007$ ), non-susceptibility to TMP-SMX was higher in Vilnius vs Panevezys (PR: 1.659, $p=0.039)$ and MDR was higher in Panevezys vs Vilnius (PR: $3.118, p=0.000$ ) and Kaunas (PR: $2.663, p=0.035$ )

in Lithuania: 93.8 in 1999, 90.0 in 2001 and $90.4 \%$ in 2006 [13].

A wide geographical variation exists in the prevalence of PNSP nasopharyngeal carriage in Europe. The rates of PNSP seen in our study (15.8\%) was higher to those observed in healthy children in Norway (1.7) [6], the Netherlands (2.7) [25], the Czech Republic (3) [8] and Estonia (6 \%) [26] before the widespread use of PCV vaccination. Contrarily, results of pre-vaccination studies conducted in Greece [27], Poland [28] and Romania [7] have shown higher rates of PNSP in healthy children:
34.7, 39.2 and $83 \%$, respectively. A decrease of resistance to penicillin was reported due to the $\mathrm{PCV}$ vaccination $[29,30]$.

According to our results, SPn susceptibility to erythromycin and clindamycin was also high (78,7 and $83.1 \%$, respectively). However, previously reported rates of nasopharyngeal SPn susceptibility to erythromycin and clindamycin were even higher among healthy preschool children in Vilnius (90.4 and $98 \%$ in 2006, respectively) [13]. A significant decrease (from $100 \%$ to 82,1 \%) of resistance to macrolides of invasive SPn isolates was also observed

Table 2 Distribution of Streptococcus pneumoniae antimicrobial non-susceptibility among age groups

\begin{tabular}{|c|c|c|c|c|c|}
\hline \multirow{2}{*}{$\begin{array}{l}\text { Age groups in } \\
\text { months }\end{array}$} & \multicolumn{4}{|c|}{ Non-susceptibility (ns) or resistance (r) to antibiotics, n (\%) } & \multirow[t]{2}{*}{$\mathrm{MDR}, \mathrm{n}(\%)$} \\
\hline & Penicillin (ns) & Erythromycin (ns) & Clindamycin (r) & TMP-SMX (ns) & \\
\hline $0-23^{\mathrm{a}}(n=92)$ & $18(19.6)$ & $21(22.8)$ & $19(20.7)$ & $25(27.2)$ & $14(15.2)$ \\
\hline $24-47(n=199)$ & 27 (13.6) & $40(20.1)$ & $31(15.6)$ & $53(26.6)$ & $23(11.6)$ \\
\hline$P$ value & 0.186 & 0.593 & 0.283 & 0.923 & 0.382 \\
\hline $48-71(n=76)$ & $13(17.1)$ & $17(22.4)$ & $12(15.8)$ & $22(28.9)$ & $9(11.8)$ \\
\hline$P$ value & 0.683 & 0.944 & 0.422 & 0.799 & 0.529 \\
\hline Total & 58 (15.8) & 78 (21.3) & $62(16.9)$ & $100(27.3)$ & $46(12.5)$ \\
\hline
\end{tabular}

TMP-SMX trimethoprim-sulphamethoxazole, MDR multidrug resistance

${ }^{\text {a }}$ Reference group for each comparison (chi-squared test) 


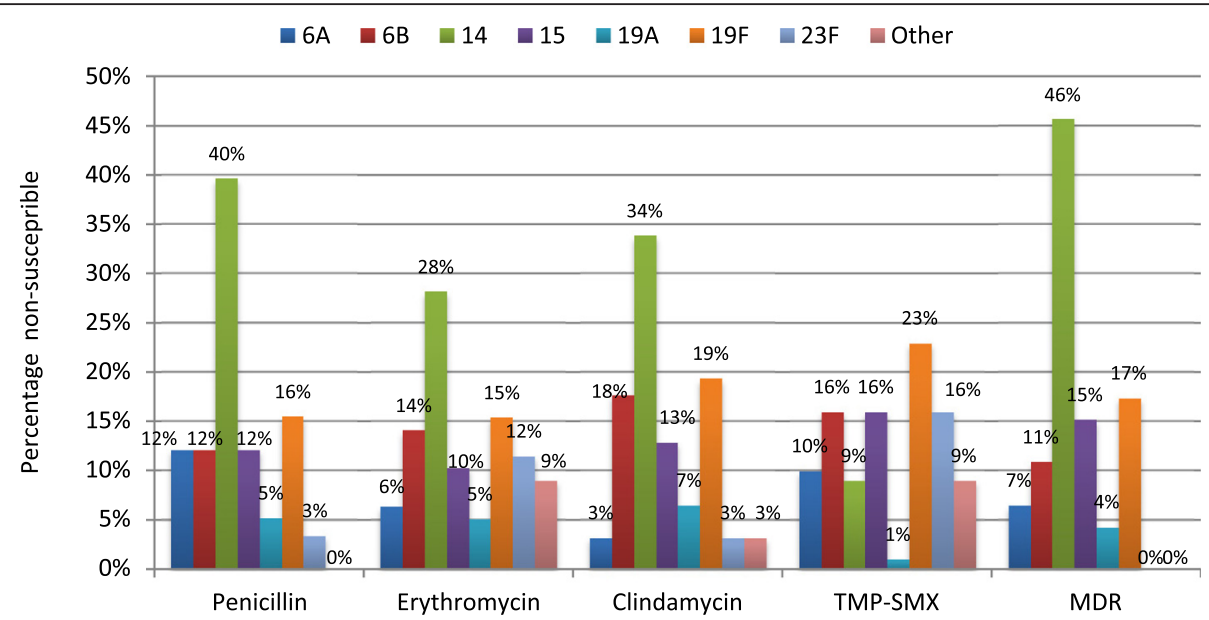

Fig. 2 The most common serotypes of non-susceptible Streptococcus pneumoniae nasopharyngeal strains. TMP-SMX - trimethoprim-sulphamethoxazole; MDR - multidrug resistance

during the period 2006-2013 in Lithuania [31]. It may be due to an increased use of macrolides in the clinical practice.

Non-susceptibility of non-invasive SPn strains to erythromycin and clindamycin varies from 1.2 [8] to 65.5 [9] and from $0.6 \%$ [8] to $49 \%$ [32] in different European countries, respectively. Our results are similar to those observed among non-invasive SPn strains in paediatric population in Poland (29.5 and $29.2 \%$, respectively) [28] and Russia (16.7 and $19.3 \%$, respectively) [33] before routine PCV vaccination in these countries.

High levels of SPn resistance to trimethoprim-sulphame thoxazole were observed previously among non-invasive strains in healthy preschool children in Lithuania [13]. Trimethoprim-sulphamethoxazole is not widely used to treat respiratory tract infections in children, therefore the non-susceptibility to trimethoprim-sulphamethoxazole decreased from $60.0 \%$ in 1999 to $46.0 \%$ in 2006 [13] and it was $27.3 \%$ in the current study. Pneumococcal resistance to trimethoprim-sulphamethoxazole was found to be high up to $66-67 \%$ in Estonia [26] and Romania [7] while the rates were lower in Norway (4.6) [6], the Netherlands (12.9) [25] and the Czech Republic (15.7\%) [8].

Our data suggest that multidrug resistance of noninvasive SPn among children in Lithuania (12.5 \%) is intermediate as compared with other European countries in the pre-PCV-vaccination era. Higher rates of MDR strains were found in Greece (25) [27], Poland (39.5) [28] and Romania (67\%) [7], while lower rates were observed in Norway (4.5) [6], Estonia (4) [26] and the Netherlands (1.9 \%) [25]. A decrease of resistance to macrolides, trimethoprim-sulphamethoxazole and MDR was reported due to the PCV vaccination [6, 30]. Resistance of SPn varies not only among the countries. We found a geographical variation of SPn resistance within the cities of the country; therefore the attention should be paid to the use of penicillin and macrolides in Panevezys and to the use of trimethoprim-sulphamethoxazole in Vilnius.

It is important to note that most studies have focused on SPn carriage in healthy children while in our study children with acute RTI were enrolled. Similarly, Mayanskiy N et al. examined antibiotic susceptibility of non-invasive SPn in children aged under six years with symptoms of an acute RTI and with chronic lung disease in Moscow, Russia. Non-susceptibility to penicillin, erythromycin and MDR was found in 28, 26 and $22 \%$ of pneumococcal strains, respectively [34]. We found a bit lower rates of SPn resistance and it may be due to the enrolment of previous healthy children or the differences in antibiotic policy.

\section{Serotype distribution of resistant S. pneumoniae strains}

Serotype distribution of resistant SPn strains has been changed during different study years in Lithuania. Serotypes $6 \mathrm{~B}, 9 \mathrm{~V}$ and $23 \mathrm{~F}$ were prevalent among PNSP strains in 2006 [13], while serogroups/serotypes 14, 19 F, 6A, 6B and 15 were the most common in the current study. Serotypes $23 \mathrm{~F}$ and $6 \mathrm{~B}$ dominated among SPn strains non-susceptible to erythromycin in 2006 [13] and serogroup 14, serotypes $19 \mathrm{~F}$ and $6 \mathrm{~B}$ were the most common according to our data. It is important to note, however, that the study sites and the type of children studied differed, which limit the comparison.

Serogroups 6, 9, 14, 19 and 23 accounted for most drugresistant SPn before widespread use of PCV in the USA and European countries [7, 27, 35-39]. Our findings are in accordance with this data with an exception of serogroup 9, which was uncommon in our study, while serogroup 15 was more prevalent. The introduction and widespread use of PCVs have changed the situation in many countries. For 
example, non-invasive PNSP isolates were mostly represented by serotypes 14, 23 F, 19 F, 6B, 9 V, 6A and 19A in France, in 2001/2002. By contrast, serotypes 19A, 19 F and non-PCV serotypes, particularly serotypes 11A, 15A, $15 \mathrm{~B} / \mathrm{C}, 29$ and $35 \mathrm{~B}$ were dominating after widespread use of PCV vaccination in 2013/2014 [35]. The previously highly prevalent resistant serotypes seem to be successfully suppressed, and the emergence of new - often less resistant, but sometimes more virulent and invasive - serotypes is observed [39].

The data suggest that vaccination could potentially reduce the carriage rate of antibiotic-resistant pneumococci in Lithuania as a majority $(67.9 \%-82.4 \%)$ of nonsusceptible SPn serotypes belonged to serotypes included in PCVs. Our study was performed before the implementation of the universal programme of $\mathrm{PCV}$ vaccination in Lithuania, therefore it provides a basis for future comparisons of resistant SPn carriage and serotype distribution between the pre- and post-vaccination era in the country. It would be also helpful in improving antimicrobial policy in Lithuania.

\section{Conclusions}

The rates of nasopharyngeal SPn susceptibility to penicillin and macrolides are high among preschool children in Lithuania, however they are lower compared with previous studies. A strict policy with respect to antibiotic prescription together with widespread use of vaccination could potentially reduce the carriage rate of antibiotic-resistant pneumococci in our country.

\begin{abstract}
Abbreviations
DCC: day care centre; ED: emergency department; EUCAST: European Committee on Antimicrobial Susceptibility Testing; MDR: multidrug resistance; MIC: minimal inhibitory concentration; PCC: primary care centres; PCV: pneumococcal conjugate vaccine; PISP: penicillin intermediate Streptococcus pneumoniae; PNSP: penicillin non-susceptible Streptococcus pneumoniae; PRSP: penicillin resistant Streptococcus pneumoniae; PSSP: penicillin susceptible Streptococcus pneumoniae; RTI: upper respiratory tract infection; SPn: Streptococcus pneumoniae; SPSS: Statistical Package for the Social Sciences; WHO: World Health Organization.
\end{abstract}

\section{Competing interests}

The authors declare that they have no competing interests.

\section{Authors' contributions}

VU conceived, initiated and designed the study, prepared all the study documents, was leading investigator. SP and DV coordinated the study, enrolled the patients in Children's Hospital, Affiliate of Vilnius University Hospital Santariskiu Klinikos. TA and IS were responsible for data management, performed the statistical analysis and drafted the manuscript. $\mathrm{JK}$ was responsible for isolating Streptococcus pneumoniae, serotyping and testing for antimicrobial susceptibility at the microbiology laboratory. All authors read and approved the final manuscript.

\section{Acknowledgements}

We would like to thank the families of the study participants for their cooperation and the physicians for including their patients into our study and collaboration.

\section{Ethics approval and consent to participate}

Vilnius Regional Biomedical Research Ethics Committee (Lithuania) approval was obtained (2011-11-08 No. 158200-11-418-118) and the parents were asked to sign an informed consent form before the child was enrolled in the study.

Consent for publication

Not applicable.

\section{Availability of data and materials}

Raw data cannot be published or used in open access databases as information about this kind of publication was not included into the Informed consent form and we have no families' approval to publish the raw data.

\section{Funding}

This work was supported/funded by Unrestricted research grant (Investigator Initiated Research) provided by Pfizer.

Received: 22 December 2015 Accepted: 6 May 2016

Published online: 20 May 2016

References

1. Bogaert D, De Groot R, Hermans PW. Streptococcus pneumoniae colonisation: the key to pneumococcal disease. Lancet Infect Dis. 2004:4(3):144-54.

2. O'Brien KL, Wolfson LJ, Watt JP, Henkle E, Deloria-Knoll M, McCall N, et al. Burden of disease caused by Streptococcus pneumoniae in children younger than 5 years: global estimates. Lancet. 2009;374(9693):893-902.

3. World Health Organization (WHO). Estimated Hib and pneumococcal deaths for children under 5 years of age, 2000. http://www.who.int/immunization/ monitoring_surveillance/burden/estimates/Pneumo_hib_2000/en. Accessed 16 May 2016

4. World Health Organization (WHO). Estimated Hib and pneumococcal deaths for children under 5 years of age, 2008. http://www.who.int/immunization/ monitoring_surveillance/burden/estimates/Pneumo_hib/en. Accessed 16 May 2016.

5. Song JH. Advances in pneumococcal antibiotic resistance. Expert Rev Respir Med. 2013;7(5):491-8.

6. Vestrheim DF, Hoiby EA, Aaberge IS, Caugant DA. Impact of a pneumococcal conjugate vaccination program on carriage among children in Norway. Clin Vaccine Immunol. 2010;17(3):325-34.

7. Falup-Pecurariu O, Bleotu L, Zavarache C, Peled N, Anton O, Robu M, et al. Streptococcus pneumoniae nasopharyngeal colonization in children in Brasov, Central Romania: high antibiotic resistance and coverage by conjugate vaccines. Pediatr Infect Dis J. 2011;30(1):76-8.

8. Zemlickova H, Urbaskova P, Adamkova V, Motlova J, Lebedova V, Prochazka B. Characteristics of Streptococcus pneumoniae, Haemophilus influenzae, Moraxella catarrhalis and Staphylococcus aureus isolated from the nasopharynx of healthy children attending day-care centres in the Czech Republic. Epidemiol Infect. 2006;134(6):1179-87.

9. Schettini Jr F, Miragliotta G, Carucci A, Mosca A, Del Vecchio GC, Laforgia N et al. Nasopharyngeal colonization of Streptococcus pneumoniae in healthy children: percentage of carriers, serotypes distribution and antibiotic resistance. Minerva Pediatr. 2003;55(5):439-45.

10. Korona-Glowniak I, Malm A. Characteristics of Streptococcus pneumoniae strains colonizing upper respiratory tract of healthy preschool children in Poland. Scientific World J. 2012;2012:732901.

11. European Centre for Disease Prevention and Control (ECDC). Antimicrobial resistance surveillance in Europe, 2014. Annual report of the European Antimicrobial Resistance Surveillance Network (EARS-Net). http://ecdc. europa.eu/en/publications/Publications/antimicrobial-resistance-europe2014.pdf. Accessed 16 May 2016.

12. Petraitienè $\mathrm{S}$, Usonis $\mathrm{V}$, Bernatonienè $\mathrm{G}$, Murauskaitė $\mathrm{G}$, Erlendsdottir $\mathrm{H}$, Bernatonienè J. Ivairių tipu streptokokų paplitimas vaikų, lankančiu ikimokyklinio ugdymo j̇staigas, viršutiniuose kvejpavimo takuose. [Distribution of various types of streptococcal infection in nasopharyngeal carriage among the children's day care attenders]. Medicinos teorija ir praktika. 2008;14(1):87-92. http://www.mtp.lt/files/MEDICINA-2008-2001-p_ 2087-2092.pdf. Accessed 16 May 2016. Lithuanian.

13. Petraitienè $S$, Bernatonienè $G$, Murauskaitè $G$, Erlendsdottir $H$, Bernatonienè J, Usonis V. S. pneumoniae nešiojimas 2-7 metu Vilniaus vaiku nosiarykleje. [Distribution of S. pneumoniae nasopharyngeal carriage among 2-7 years of age children in Vilnius]. Vaiku pulmonologija ir alergologija. 2009;XII(1):4119-30. Lithuanian. 
14. Ministry of Health of Lithuania. Lietuvos Respublikos vaiku profilaktiniu skiepijimy kalendorius. [Calendar of prophylatic immunisations of children Republic of Lithuania 2014 [July 07]]. Lithuanian. http://www3.Irs.lt/pls/ inter3/dokpaieska.showdoc_p?p_id=466527. Accessed 16 May 2016.

15. Dagan R. Impact of pneumococcal conjugate vaccine on infections caused by antibiotic-resistant Streptococcus pneumoniae. Clin Microbiol Infect. 2009; 15 Suppl 3:16-20.

16. Usonis V, Stacevičienè I, Petraitienè S, Vaičiūnienè D, Alasevičius T, Kirslienė J. Streptococcus pneumoniae nasopharyngeal colonisation in children aged under six years with acute respiratory tract infection in Lithuania, February 2012 to March 2013. Euro Surveill. 2015;20(13):34-41.

17. Petraitienè S, Alasevičius T, Stacevičienè I, Vaičiūnienè D, Kačergius T, Usonis $\checkmark$. The influence of Streptococcus pneumoniae nasopharyngeal colonization on the clinical outcome of the respiratory tract infections in preschool children. BMC Infect Dis. 2015;15(1):403.

18. O'Brien KL, Millar EV, Zell ER, Bronsdon M, Weatherholtz R, Reid R, et al. Effect of pneumococcal conjugate vaccine on nasopharyngeal colonization among immunized and unimmunized children in a community-randomized trial. J Infect Dis. 2007:196(8):1211-20.

19. Varon E, Levy C, De La Rocque F, Boucherat M, Deforche D, Podglajen I, et al. Impact of antimicrobial therapy on nasopharyngeal carriage of Streptococcus pneumoniae, Haemophilus influenzae, and Branhamella catarrhalis in children with respiratory tract infections. Clin Infect Dis. 2000;31(2):477-81.

20. Hare KM, Stubbs E, Beissbarth J, Morris PS, Leach AJ. Swab transport in Amies gel followed by frozen storage in skim milk tryptone glucose glycerol broth (STGGB) for studies of respiratory bacterial pathogens. J Microbiol Methods. 2010;81(3):253-5.

21. Satzke C, Turner P, Virolainen-Julkunen A, Adrian PV, Antonio M, Hare KM, et al. Standard method for detecting upper respiratory carriage of Streptococcus pneumoniae: updated recommendations from the World Health Organization Pneumococcal Carriage Working Group. Vaccine. 2013; 32(1):165-79.

22. O'Brien $\mathrm{KL}$, Nohynek $\mathrm{H}$, World Health Organization Pneumococcal Vaccine Trials Carriage Working G. Report from a WHO Working Group. Standard method for detecting upper respiratory carriage of Streptococcus pneumoniae. Pediatr Infect Dis J. 2003:22(2):e1-11.

23. European Committee on Antimicrobial Susceptibility Testing (EUCAST). http://www.eucast.org. Accessed 16 May 2016.

24. Richter SS, Heilmann KP, Dohrn CL, Riahi F, Beekmann SE, Doern GV. Changing epidemiology of antimicrobial-resistant Streptococcus pneumoniae in the United States, 2004-2005. Clin Infect Dis. 2009;48(3):e23-33.

25. Bogaert D, Sluijter M, Toom NL, Mitchell TJ, Goessens WH, Clarke SC, et al. Dynamics of pneumococcal colonization in healthy Dutch children. Microbiology. 2006;152(Pt 2):377-85.

26. Tamm E, Naaber P, Maimets M, Oona M, Koljalg S, Lutsar I. Antimicrobial susceptibility and serogroup/serotype distribution of nasopharyngeal isolates of Streptococcus pneumoniae in healthy Estonian children in 19992003. Clin Microbiol Infect. 2007;13(8):824-6.

27. Poulakou G, Katsarolis I, Matthaiopoulou I, Tsiodras S, Kanavaki S, Hatzaki D, et al. Nationwide surveillance of Streptococcus pneumoniae in Greece: patterns of resistance and serotype epidemiology. Int J Antimicrob Agents. 2007;30(1):87-92.

28. Korona-Glowniak I, Niedzielski A, Malm A. Upper respiratory colonization by Streptococcus pneumoniae in healthy pre-school children in south-east Poland. Int J Pediatr Otorhinolaryngol. 2011;75(12):1529-34.

29. Angoulvant F, Cohen R, Doit C, Elbez A, Werner A, Bechet S, et al. Trends in antibiotic resistance of Streptococcus pneumoniae and Haemophilus influenzae isolated from nasopharyngeal flora in children with acute otitis media in France before and after 13 valent pneumococcal conjugate vaccine introduction. BMC Infect Dis. 2015:15:236.

30. Daana M, Rahav G, Hamdan A, Thalji A, Jaar F, Abdeen Z, et al. Measuring the effects of pneumococcal conjugate vaccine (PCV7) on Streptococcus pneumoniae carriage and antibiotic resistance: the Palestinian-Israeli Collaborative Research (PICR). Vaccine. 2015;33(8):1021-6.

31. European Centre for Disease Prevention and Control (ECDC). Susceptibility of Streptococcus pneumoniae Isolates to macrolides in Lithuania, 2006-2013. http://ecdc.europa.eu/en/healthtopics/antimicrobial_resistance/database/Pages/ table_reports.aspx. Accessed 16 May 2016.

32. Sa-Leao R, Nunes S, Brito-Avo A, Alves CR, Carrico JA, Saldanha J, et al. High rates of transmission of and colonization by Streptococcus pneumoniae and
Haemophilus influenzae within a day care center revealed in a longitudinal study. J Clin Microbiol. 2008:46(1):225-34.

33. Katz A, Leibovitz E, Timchenko VN, Greenberg D, Porat N, Peled N, et al. Antibiotic susceptibility, serotype distribution and vaccine coverage of nasopharyngeal and oropharyngeal Streptococcus pneumoniae in a day-care centre in St. Petersburg, Russia. Scand J Infect Dis. 2007;39(4):293-8.

34. Mayanskiy N, Alyabieva N, Ponomarenko O, Lazareva A, Katosova L, Ivanenko A, et al. Serotypes and antibiotic resistance of non-invasive Streptococcus pneumoniae circulating in pediatric hospitals in Moscow, Russia. Int J Infect Dis. 2014;20:58-62.

35. Cohen R, Varon E, Doit C, Schlemmer C, Romain O, Thollot F, et al. A 13year survey of pneumococcal nasopharyngeal carriage in children with acute otitis media following PCV7 and PCV13 implementation. Vaccine. 2015;33(39):5118-26

36. Centers for Disease Control and Prevention (CDC). Pneumococcal Disease. Drug Resistance. http://www.cdc.gov/pneumococcal/drug-resistance.html. Accessed 16 May 2016.

37. Petrosillo N, Pantosti A, Bordi E, Spano A, Del Grosso M, Tallarida B, et al. Prevalence, determinants, and molecular epidemiology of Streptococcus pneumoniae isolates colonizing the nasopharynx of healthy children in Rome. Eur J Clin Microbiol Infect Dis. 2002;21(3):181-8.

38. Bayraktar MR, Durmaz B, Kalcioglu MT, Durmaz R, Cizmeci Z, Aktas E. Nasopharyngeal carriage, antimicrobial susceptibility, serotype distribution and clonal relatedness of Streptococcus pneumoniae isolates in healthy children in Malatya. Turkey Int J Antimicrob Agents. 2005;26(3):241-6.

39. Tothpal A, Kardos S, Hajdu E, Nagy K, Linden M, Dobay O. Nasal carriage of Streptococcus pneumoniae among Hungarian children before the wide use of the conjugate vaccine. Acta Microbiol Immunol Hung. 2012;59(1):107-18.

\section{Submit your next manuscript to BioMed Central and we will help you at every step:}

- We accept pre-submission inquiries

- Our selector tool helps you to find the most relevant journal

- We provide round the clock customer support

- Convenient online submission

- Thorough peer review

- Inclusion in PubMed and all major indexing services

- Maximum visibility for your research

Submit your manuscript at www.biomedcentral.com/submit

C) Biomed Central 